Personalidade Acadêmica Homenageada:

Augustus B. Cochran III (Agnes Scott College)

\title{
A TOMADA DE DECISÃO APOIADA CONDUZIDA AO PODER JUDICIÁRIO É UMA RESTRIÇÃO À PLENA CAPACIDADE DOS DEFICIENTES?
}

\section{IS THE DECISION-MAKING DECISION-MAKING TO JUDICIAL POWER A RESTRICTION ON THE FULL CAPACITY OF THE DISABLED?}

\begin{abstract}
ANDRÉ CESAR DE MELLO
É advogado; integrante da Comissão da Criança e do Adolescente da OAB/PR; pesquisador do Núcleo de Estudos em Direito Civil-Constitucional - Grupo de Pesquisa Civil-Constitucional Virada de Copérnico pela Universidade Federal do Paraná - UFPR; pesquisador no Centro Universitário Curitiba - UNICURITIBA; também é pesquisador na Faculdade de Pinhais - FAPI. É pós-graduando em Direito de Família e Sucessões na Academia Brasileira de Direito Constitucional ABDConst e bacharel em Direito pelo Centro Universitário Curitiba - UNICURITIBA .
\end{abstract}

\section{ADRIANA MARTINS}

Mestre em Direito Empresarial. Especialista em Direito Processual Civil. Professora na graduação e pós graduação e orientadora de trabalhos de conclusão de curso nas áreas de Direito Civil, Família, Sucessão e Empresarial no Centro Universitário Curitiba - UNICURITIBA. Professora e orientadora de trabalhos de conclusão de curso na graduação de direito de Família e Sucessões do Centro Universitário UNINTER. Professora e orientadora de trabalhos de conclusão de pós-graduação em Direito de Família e Sucessões no Curso JURÍDICO. Professora Pesquisadora do Núcleo de Estudos em Direito Civil-Constitucional - Grupo de Pesquisa de CivilConstitucional Virada de Copérnico pela Universidade Federal do Paraná- UFPR. Coordenadora do Grupo de Pesquisa e Extensão Temas Contemporâneos de Direito 


\section{Personalidade Acadêmica Homenageada:}

\section{Augustus B. Cochran III (Agnes Scott College)}

de Família junto ao Centro Universitário Curitiba - UNICURITIBA. Advogada nas áreas cível, família e sucessões.

\section{RESUMO}

A Convenção Internacional Sobre Direitos das Pessoas com Deficiência trouxe novo paradigma para a capacidade civil no Direito brasileiro e a Lei Brasileira de Inclusão da Pessoa com Deficiência trouxe inúmeras prerrogativas àqueles que anteriormente eram, direta e indiretamente, discriminados pela sociedade como incapazes e em estado de vulnerabilidade (RAIOL, 2019). Dentre tantas alterações legais, o artigo 116 da aludida lei incluiu o artigo 1.783-A do Código Civil, instituindo a denominada tomada de decisão apoiada. No seu $\S 6^{\circ}$, preconiza-se que, se eventual negócio jurídico trouxer prejuízos ou riscos, havendo divergência entre os apoiadores e o apoiado, após a oitiva do Ministério Público o juiz decidirá sobre a questão controvertida. Devido à alteração do paradigma, as pessoas com deficiência guardam presunção de plena capacidade civil, podendo instituir no mínimo dois apoiadores para auxiliá-lo nas decisões sobre a vida civil, privilegiando a autonomia daquelas pessoas. Contudo, se a tomada de decisão apoiada for conduzida ao Poder Judiciário, poder-se-á levar à nulificação de determinado negócio jurídico. Seria isso, portanto, uma infração à plena capacidade dos deficientes? Como metodologia científica, utilizou-se o método dedutivo de realização da pesquisa, amparando-se em pesquisa bibliográfica e na análise de artigos científicos, assim como fichamento foi amplamente utilizado. Concluindo-se, tem-se que há quem defenda que o $§ 6^{\circ}$ seja inconstitucional e inconvencional. Sustenta-se que não há qualquer delimitação da hipótese de incidência do $\S 6^{\circ}$. Considerando que pessoas com deficiência podem ter alguma dificuldade em decidir sobre negócios jurídicos, muitos negócios jurídicos poderão supostamente trazer prejuízos a ele, de modo que se delegará ao juiz a decisão sobre a validade do referido negócio jurídico., mitigando a capacidade do plenamente capaz (PAULA, 2016). Argumenta-se também que 0 deficiente, com sua capacidade de fato preservada, pode 


\section{Personalidade Acadêmica Homenageada:}

\section{Augustus B. Cochran III (Agnes Scott College)}

compreender os ricos que o negócio jurídico pode gerar, não sendo possível a intervenção judicial (MENEZES, 2015). E mais: Há quem conclua também que o referido parágrafo andou na contramão do que se esperava, sendo inconstitucional e inconvencional, pois retirou a "capacidade plena, independência, autossuficiência e autonomia individual" e a "igualdade de oportunidades e respeito às diferenças" (SILVA; PAIVA; RICHARTZ, 2018). Ademais disso, sustenta-se que a tomada de decisão apoiada é facultativa e não impõe a incapacidade do agente, sendo absolutamente desarrazoado que o negócio seja anulado nesse caso (VIEIRA, 2019). Além disso, sustenta-se que essa será uma nova hipótese de anulação inadvertida do negócio jurídico. (RIBEIRO, 2015). Ainda, Maurício Requião diz que, se a lei prevê que apenas nos negócios jurídicos relevantes a problemática poderá ser encaminhada ao Judiciário, prevalecerá, em contrapartida, a escolha do apoiado nos casos de menor monta (REQUIÃO, 2016). Por outro lado, argumenta-se que o referido dispositivo presume que todo negócio jurídico traz consigo prejuízos e, mesmo assim, ouvido o Ministério Público, o juiz poderá substituir a vontade do deficiente (VIGLIAR, 2018). Ainda: sustenta-se que, havendo divergência entre apoiadores e apoiado, é possível a anulabilidade do ato, desde que provada a incapacidade ou deficiência incapacitante para o exercício da capacidade de fato e dos prejuízos e riscos, além de outras alegações indicadas no capítulo anterior (DESCONSI; DE SOUTO GOULART, 2017). A conclusão a que se chega, observando-se todo o arcabouço argumentativo apresentado, é a de que não há entendimento uníssono sobre a (ir)regularidade do $§ 6^{\circ}$ do artigo 1.783-A do Código Civil. Há quem sustente ser inconstitucional e inconvencional, sendo, portanto, inaplicável. Há quem entenda que se trata de uma nova hipótese de anulabilidade do negócio jurídico.

PALAVRA-CHAVE: Deficiência; Decisão Apoiada; Judiciário; Incongruências. 
Personalidade Acadêmica Homenageada:

Augustus B. Cochran III (Agnes Scott College)

\section{REFERÊNCIAS}

DESCONSI, Raphaela Regina; DE SOUTO GOULART, Fernanda Sell. Análise da validade do negócio jurídico celebrado por pessoa com deficiência intelectual. Anais do Congresso Catarinense de Direito Processual Civil, Itajaí, agosto de 2017. Disponível em: < https://siaiap32.univali.br/seer/index.php/accdp/article/view/11882>. Acesso em: 03 jun. 2019.

MENEZES, Joyceane Bezerra de. 0 direito protetivo no Brasil após a convenção sobre a proteção da pessoa com deficiência: impactos do novo CPC e do estatuto da pessoa com deficiência. Civilistica.com, Rio de Janeiro, a. 4, n. 1, p. 1618, jan./jun., 2015.

PAULA, Bárbara Rodrigues de. O Estatuto da Pessoa com Deficiência: Uma Análise Crítica Sobre o Regime das Incapacidades e o Instituto da Tomada de Decisão Apoiada. 2016. 39f. Monografia (Graduação em Direito). Faculdade de Direito da Universidade Federal de Juiz de Fora, Juiz de Fora, 2016. Disponível em: $<$ https://acervodigital.ufpr.br/bitstream/handle/1884/45996/49.pdf?sequence=1\&isAllo wed=y>. Acesso em: 15 abr. 2019.

RAIOL, Raimundo Wilson Gama; DO NASCIMENTO NONATO, Domingos. Mais Vulnerabilizadas à Violência Urbana: Pessoas em Situação de Rua e a Suposta Segurança Pública. Revista Jurídica, v. 53, n. 4, p. 633-658, 2019.

REQUIÃO, Maurício. As mudanças na capacidade e a inclusão da tomada de decisão apoiada a partir do Estatuto da Pessoa com Deficiência. Revista de Direito Civil Contemporâneo, v. 6, p. 37-54, 2016.

RIBEIRO, lara Pereira. A capacidade civil da pessoa com deficiência intelectual. In: XXIV Congresso Nacional do CONPEDI - UFMG/FUMEC/DOM Helder Câmara, 2015, Florianópolis: Direito Civil Contemporâneo II. Disponível em:<https://www.academia.edu/37448400/A_CAPACIDADE_CIVIL_DA_PESSOA_C OM_DEFICI\%C3\%8ANCIA_INTELECTUAL_THE_CIVIL_LEGAL_CAPACITY_OF_N ATURAL_PERSON_WITH_INTELLECTUAL_DISABBILITIES>. Acesso em: $\overline{2} 1 \overline{a b}$. 2019. p. $114-115$.

ROSENVALD, Nelson. A tomada de decisão apoiada: primeiras linhas sobre um novo modelo jurídico promocional da pessoa com deficiência. Revista IBDFAM: Famílias e Sucessões, Belo Horizonte, n. 10, p. 11-19, jul./ago. 2015.

SILVA, Santo et al. Tomada de Decisão Apoiada: Aspectos Constitucionais e de Direito Internacional. Revista FSA, v. 15, n. 6; p. 95-112, 2018.

VIEIRA, Cristiana de Souza. A Capacidade Civil da Pessoa com Deficiência Intelectual. 2016. 67f. Monografia (Graduação em Direito). Faculdade de Direito da Universidade Federal do Maranhão, São Luís, 2016. Disponível em: < 
Personalidade Acadêmica Homenageada:

Augustus B. Cochran III (Agnes Scott College)

https://monografias.ufma.br/jspui/handle/123456789/1669>. Acesso em:21 abr. 2019.

VIGLIAR, Jose Marcelo Menezes. Tomada de decisão apoiada: aspectos sobre a confiança e vontade da pessoa com deficiência. Revista Brasileira da Advocacia, São Paulo: Ed. RT, vol. 8, ano 3, p. 215, jan.-mar. 2018.

VIGOLO, Alessandra Rizzardo. Alterações no instituto da interdição: confrontações entre o novo código de processo civil e o estatuto da pessoa com deficiência. 2017. 33f. Monografia (especialização em Processo Civil). Especialização da Universidade Federal do Rio Grande do Sul. 2017. Disponível em: $<$ https://www.lume.ufrgs.br/bitstream/handle/10183/184589/001079974.pdf?sequenc $\mathrm{e}=1$ \&isAllowed $=\mathrm{y}>$. Acesso em: 22 abr. 2019. 